\title{
Influência da loja conceito na imagem da marca e intenção de compra de artigos de vestuário
}

Iinfluence of the concept store on the brand image and in the purchase intention of apparel articles

\section{Marcos Roberto Luppe ${ }^{*}$; Ana Clara da Silva Almeida ${ }^{2}$; Nádia Nagata Hirano ${ }^{3}$; Helder de Souza Aguiar ${ }^{4}$}

${ }^{1 *} \mathrm{EACH} / \mathrm{USP}$ - Professor Doutor - Rua Arlindo Béttio, 1000, prédio I1, sala 352H - Jardim Keralux - 03828-000 - São Paulo - SP - Brasil <mluppe@usp.br>

${ }^{2,3} \mathrm{EACH} / \mathrm{USP}$ - Discente - Rua Arlindo Béttio, prédio I1, sala 352H - Jardim Keralux - 03828-000 - São Paulo, SP - Brasil

${ }^{4}$ Anhembi-Morumbi - Professor - Rua Capote Valente, 1335, apt. 94 - Pinheiros - 05409-003 - São Paulo, SP - Brasil

\section{Resumo}

O presente trabalho buscou entender se lojas conceito influenciam na imagem da marca e intenção de compra de produtos na loja, analisando especificamente empresas do segmento de vestuário no mercado brasileiro que utilizam estratégia "fast fashion". A fim de compreender as razões pelas quais as empresas decidem implementar uma loja conceito e entender as principais diferenças entre uma loja tradicional (padrão) e uma loja conceito, foi realizada uma pesquisa qualitativa com o gestor de uma grande empresa que utiliza estratégia "fast fashion" e que implementou lojas conceitos no Brasil, e uma pesquisa quantitativa que consistiu em um estudo quase-experimental em que um grupo foi apresentado ao estímulo da loja padrão e o outro, de uma loja conceito. Para não haver interferências nas respostas em razão da imagem da marca, buscou-se elaborar o estímulo baseado em uma marca de loja de vestuário ainda não presente no Brasil. As análises obtidas no estudo verificaram que a loja conceito exerce uma influência positiva em relação à imagem da marca que utiliza essa estratégia, porém a intenção de compra dos consumidores não sofre uma influência significativa.

Palavras-chave: comportamento do consumidor, fast fashion, lojas de vestuário

\begin{abstract}
The present study sought to understand if there is an influence of the concept store in the brand image and purchase intention, analyzing specifically clothing segment companies in the Brazilian market that use fast fashion strategy. In order to understand the reasons why companies decide to implement a concept store and understand the main differences between a traditional (standard) and a concept store, a qualitative research was conducted with a manager of a large company that uses fast fashion strategy and implemented concept stores in Brazil. In addition, a quantitative study was carried out, consisting on an experimental study where one group was presented to a stimulus based on representing a standard store and the other one, a concept store. In order to avoid interferences in the answers, we tried to elaborate the stimulus based on a brand of apparel store not yet present in Brazil. The results obtained in the study verified that a concept store exerts a positive influence on brand image that uses this strategy, however there's not a significant influence on purchase intention.
\end{abstract}

Keywords: consumer behavior, fast fashion, apparel stores

\section{Introdução}

Em um cenário competitivo, com um aumento no número de "players" no mercado, massificação dos produtos e exigências cada vez maiores dos clientes, torna-se cada vez mais necessária a elaboração de estratégias que visam à criação de associações positivas para a marca, de forma a melhorar a sua imagem e aumentar o seu poder de influência no comportamento dos consumidores, tornando-a, realmente, um diferencial competitivo. Uma das estratégias que vêm sendo usadas e que tem se mostrado muito importante consiste em oferecer uma experiência de compra diferenciada e mais prazerosa (Newsom et al., 2009; Serrentino, 2016).

A partir da década de 90, com um aumento significativo no número de "Stock Keeping Unit"
[SKU's] e de "players" no mercado, a escolha da marca começou a se dar no ponto de venda (Consoli et al., 2011; Alvarez, 2012). Desta forma, o varejo ganha força e se mostra necessário, cada vez mais, aperfeiçoar o ambiente de compra de forma a potencializar suas vendas. De acordo com Darden et al. (1983), a correlação entre a crença dos consumidores sobre a atratividade física de uma loja e suas intenções de suporte à marca sugerem que os aspectos visuais do ponto de venda podem ser significantes para a escolha da loja e para a intenção de compra do consumidor.

A questão da atratividade da loja é muito presente no varejo de moda. Ipar e Almeida (2011) avaliaram que, dos anos 1960 aos dias mais atuais, o varejo de moda do Brasil passou por grandes mudanças nos hábitos 
dos consumidores e na forma com que os varejistas agem dentro do mercado. Caetano $(2013)^{1}$ resaltou que, atualmente, as opções e ofertas são as mais variadas, e que o grande desafio do marketing das empresas varejistas é de criar vantagem competitiva por meio de novas e diversas estratégias e de vencer o desafio da fidelização, ou seja, de manter a conquista do cliente.

A estrutura da loja, nesse contexto, mostra-se como um diferencial para a marca. Com o intuito, portanto, de projetar uma loja que melhore a imagem da marca, crie associações positivas e aumente a intenção de compra, surge a estratégia baseada na abertura de lojas conceito. Segundo Frederico (2014), as lojas conceito são feitas e gerenciadas de forma a criar uma atmosfera e experiência de compra que reflitam o posicionamento da marca. Com a loja conceito, as marcas têm como objetivo se diferenciarem e aumentarem o seu prestígio (Fionda e Moore, 2009).

As lojas conceito são muito reconhecidas quando pertencentes a famosas marcas de luxo que têm como público-alvo pessoas com maior poder aquisitivo e que buscam experiências de compra diferenciadas. Entretanto, esse tipo de estratégia não tem ficado restrita apenas ao setor de luxo. Mesmo empresas de vestuário que atuam com estratégia "fast fashion" têm investido nesse tipo de loja, visando possivelmente a uma melhoria na imagem de suas marcas.

Uma loja conceito pode ser definida por ter algumas características principais como: 1) dar suporte a uma única marca de produto; 2) pertencente ao fabricante da marca; 3) intenção de reforçar a marca ao invés de somente vender um produto para gerar lucro (Kozinets et al., 2002).

As marcas varejistas utilizam a loja conceito com o intuito de se diferenciarem e aumentarem o seu prestígio e visibilidade, já que pode haver dificuldade por parte dos canais tradicionais em expressar o conceito da marca (Fionda e Moore, 2009).

Essas lojas são distintas de outras lojas da mesma empresa em questão de escala, design e custos de operação, sendo as lojas conceito significantemente maiores que as tradicionais. No geral, as lojas conceito apresentam localizações privilegiadas, têm sua arquitetura de loja projetada por arquitetos famosos e, ainda segundo Plazibat e Brajevic (2011), fazem uma significativa contribuição para a imagem da marca, com novos clientes inspirados e encorajados a comprar produtos da marca depois de terem visitado a loja conceito.

Pode-se perceber, portanto, como um ambiente de loja diferenciado, de fato, exerce uma influência nos consumidores. A loja conceito, nesse contexto, surge como um ponto de venda de destaque, que eleva a imagem da marca e pode contribuir para aumentar a propensão do "shopper" em comprar produtos. Desta forma, teoriza-se que:

H1: Há uma relação positiva entre uma boa avaliação da loja conceito e a intenção de compra dos produtos da marca.

Nesse contexto, há um alto investimento nesse tipo de loja para solidificar o conceito e o prestígio da marca (Fionda e Moore, 2009), dado que o consumidor tende a perceber a unicidade desta ao ter uma experiência de compra diferenciada (Carpenter e Fairhurst, 2005). As lojas conceito, portanto, tem como um dos seus maiores objetivos aumentar a visibilidade da marca, além de atrair diferentes consumidores através de um layout diferenciado que busca traduzir o posicionamento da loja. Visto que as lojas conceito têm como objetivo comunicar e fortalecer a marca, mostra-se importante entender se essa associação realmente é efetiva na mente dos consumidores e se a loja conceito influencia, de fato, a imagem que os consumidores têm da marca. Assim, pode-se levantar uma $2^{\text {a }}$ hipótese:

H2: Há uma relação positiva entre uma boa avaliação da loja conceito e a imagem da marca.

De acordo com dados da Euromonitor, o setor varejista de vestuário brasileiro atingiu um volume de vendas de $\mathrm{R} \$ 93$ bilhões em 2015, representando 2,54\% do Produto Interno Bruto [PIB] de serviços (S/A Restoque, 2016) ${ }^{2}$.

Esse contexto da recente inauguração de lojas conceito de empresas de vestuário que atuam com estratégia "fast fashion" é aliado a uma desaceleração do setor no Brasil, com diminuição de $32,5 \%$ no faturamento da cadeia têxtil e de confecção, além de uma retração no varejo de moda, que em 2015 apresentou uma queda de 8\% enquanto a previsão para 2016 é uma queda de 4,8\% (ABIT, 2016).

Nesse sentido, mostra-se relevante um maior entendimento de como a abertura desse modelo de loja diferenciado pode potencializar as vendas de uma empresa ou mesmo mudar a opinião de seus consumidores e como ela é vista por seus clientes, de modo a melhorar a performance da marca e minimizar as consequências da retração do setor.

Além disso, devido à falta de publicações que aliam a estratégia "fast fashion" a lojas conceito, é importante entender como as duas estratégias podem estar alinhadas em uma mesma empresa. Por esta razão, no presente trabalho, as questões citadas serão discutidas

${ }^{1}$ Caetano, C.C. 2013. O cross-branding e a cocriação no âmbito do varejo de moda. São Paulo. Dissertação (Mestrado em Textil e Moda) - Programa de Pós-Graduação em Têxtil e Moda, Escola de Artes, Ciências e Humanidades da Universidade de São Paulo.

${ }^{2}$ S/A, Restoque. 2016. O Setor Varejista no Brasil. Disponível em: <http:/ www.restoque.com.br/conteudo_pt.asp?idioma $=0 \&$ conta $=28 \&$ tipo $=41515>$. Acesso em: 09 nov. 2016. 
exclusivamente para empresas que atuam com estratégia "fast fashion", mas que abriram, paralelamente, lojas conceito.

Desta forma, configura-se como principal objetivo do trabalho identificar o grau de influência das lojas conceito na imagem da marca e na intenção de compra dos consumidores em empresas do segmento de vestuário no mercado brasileiro. Como objetivos secundários, têm-se: avaliar as principais diferenças entre as lojas conceito e as lojas tradicionais e compreender as razões que motivam a abertura de lojas conceito por essas empresas.

$\mathrm{Na}$ próxima seção serão abordados os tópicos relacionados à pesquisa, como o método, o universo de pesquisa, a definição das amostras a serem utilizadas e a coleta de dados. $\mathrm{Na}$ sequência, serão apresentados os resultados obtidos nas pesquisas realizadas e, por fim, serão discutidas as conclusões, limitações e possíveis extensões do presente estudo.

\section{Material e Métodos}

A fim de entender se há influência da abertura de lojas conceito por marcas que usam a estratégia "fast fashion" na imagem da marca e na intenção de compra - principal objetivo do trabalho - foram realizados dois tipos de pesquisa, uma com abordagem qualitativa e outra quantitativa.

A pesquisa qualitativa foi realizada no dia 09 out. 2016 e consistiu em uma entrevista em profundidade com um gestor de uma grande empresa que possui estratégia "fast fashion" e explora no Brasil a abertura de lojas conceito. $\mathrm{Na}$ entrevista foram abordados tópicos como a estratégia utilizada pela empresa, resultados esperados, dificuldades encontradas, além de uma descrição mais aprofundada sobre as características da loja, na perspectiva do gestor. Os dados coletados na entrevista foram analisados através do método de análise do discurso.

A pesquisa quantitativa foi realizada durante $\mathrm{O}$ mês de novembro de 2016 e consistiu em um estudo quase-experimental. Buscou-se entender a opinião dos respondentes em relação a uma loja padrão e uma loja conceito, objetivando identificar se há uma mudança na percepção da imagem da marca e na intenção de compra dos consumidores quando as duas lojas são comparadas. Sendo assim, foi estabelecido como variável independente o tipo de loja (loja padrão ou loja conceito) e variável dependente à imagem da marca e à intenção de compra.

A pesquisa quantitativa continha estímulos apresentados a dois grupos diferentes de respondentes: um dos grupos foi apresentado a uma loja padrão e a outro grupo uma loja padrão e uma loja conceito. Para que o fator conhecimento da marca não influenciasse os resultados, buscou-se elaborar o estímulo baseado em uma grande empresa sueca de vestuário que ainda não está presente no mercado brasileiro e que é um dos principais players nesse setor no mercado mundial. Essa empresa foi denominada empresa $\mathrm{X}$ neste trabalho. Os estímulos apresentados consistiram em uma descrição sobre a marca e fotos da loja. Visto isso, o grupo de controle, apresentado somente à loja padrão, recebeu o seguinte estímulo:

"A empresa X é uma rede multinacional sueca de moda presente em 41 países que contém mais de 3000 lojas ao redor do mundo. A rede de lojas tem a proposta de oferecer moda e qualidade a um preço acessível, tendo uma grande variedade de peças tanto para o público feminino, quanto para o masculino. Essa empresa irá iniciar as operações no Brasil com a abertura de lojas em diferentes shoppings, similares às lojas de departamento de vestuário já existentes no país. Abaixo estão fotos que representam como é uma loja padrão da empresa X."

Foram então mostradas fotos da entrada principal/ vitrine da loja e da disposição dos produtos.

O grupo experimental, por sua vez, foi apresentado aos dois tipos de loja. Foi mostrado o mesmo texto introdutório do questionário do grupo de controle juntamente com as fotos da loja padrão. Logo depois, foi mostrado o texto abaixo:

"Além da loja padrão, a empresa X também abrirá uma loja conceito na Oscar Freire, uma famosa rua de São Paulo que abriga lojas de marcas luxuosas. Essa loja conceito da empresa $\mathrm{X}$ será maior, terá um ambiente diferenciado formatado por arquitetos famosos, uma localização privilegiada e uma inovadora forma de disposição dos produtos. Abaixo, estão fotos que representam como é uma loja conceito da empresa X".

A seguir, foram então mostradas fotos da entrada principal/vitrine da loja e da disposição dos produtos da loja conceito.

A amostra total da pesquisa foi de 620 respondentes, sendo 323 entrevistados pertencentes ao grupo de controle (com o questionário da loja padrão) e 297 respondentes que compuseram o grupo experimental (que foram apresentados também à loja conceito). Para responder a pesquisa, o entrevistado deveria, necessariamente, frequentar lojas de departamento de vestuário. A coleta de dados foi realizada por meio da plataforma virtual Qualtrics.

As escalas utilizadas para a construção do questionário foram a escala Likert para determinar a intenção de compra e a escala de diferencial semântico para avaliar a imagem da marca. Além disso, foram também construídas escalas para identificar se os dois tipos de loja tinham sido percebidos de forma diferente pelos grupos, checando, dessa forma, a manipulação feita. Essas escalas de controle da manipulação também foram do tipo Likert e de diferencial semântico. 
Ademais, foram também incluídas questões de caracterização do respondente, como idade, sexo, renda, escolaridade e hábitos de compra em lojas de departamento de vestuário, buscando entender de forma mais precisa o consumidor desse tipo de loja.

Primeiramente, foi feito um pré-teste dos questionários, onde almejou-se eliminar possíveis problemas presentes no questionário e deixando-o claro para qualquer respondente.

Com todos os dados coletados, foi possível a realização de análises que buscaram compreender se a loja conceito influencia ou não na imagem da marca e na intenção de compra. Para isso, foram feitas análises de acordo com a frequência das respostas além de análises estatísticas através do software "Statistical Package for the Social Sciences" [SPSS], como teste de confiabilidade, análise fatorial e Teste $\mathrm{T}$.

\section{Resultados e Discussão}

Os resultados das duas pesquisas do presente trabalho foram divididos em duas etapas, sendo analisado primeiro a pesquisa qualitativa, e em seguida, a quantitativa.

A análise dos dados da pesquisa qualitativa consistiu em um agrupamento das respostas da entrevista em profundidade com a Coordenadora de "Visual Merchandising" de uma grande multinacional do segmento de vestuário e que atua no Brasil há muitos anos. Essa empresa foi denominada no presente estudo como: empresa Y.

Os dados da pesquisa quantitativa foram analisados através do software SPSS, onde buscou-se observar a significância das variáveis imagem da marca e intenção de compra, estabelecidas nas hipóteses de pesquisa.

\section{Resultados da pesquisa qualitativa}

Com o intuito de entender as razões que motivaram os gestores de empresas que utilizam estratégia "fast fashion" a abrir lojas conceitos, foi realizada uma entrevista com a Coordenadora de "Visual Merchandising" da empresa Y. Escolheu-se a marca dessa empresa para realizar a pesquisa qualitativa, pois foi uma das primeiras empresas que utilizam estratégia "fast fashion" a inaugurar uma loja conceito no Brasil. A respondente foi uma das responsáveis pelo projeto de implementação da primeira loja conceito da empresa Y em um shopping center na cidade de São Paulo.

Dentre as questões abordadas, foi perguntado quais as principais motivações que a empresa $\mathrm{Y}$ tinha para a abertura da loja conceito. A respondente comentou que é sempre importante ter uma loja conceito pensando, principalmente, em deixar a marca em evidência. Visto isso, escolhe-se sempre o melhor local e o melhor posicionamento, com um conceito único e exclusivo que busca atender não só os clientes da empresa Y como também conseguir alcançar outro tipo de cliente. Na loja conceito instalada no shopping center são realizados todos os principais eventos (exemplo: lançamento de coleção com estilistas e "influencers"), recebendo seu público-alvo e também públicos que a empresa não atinge normalmente por meio de suas lojas tradicionais (principalmente público A-B). Assim, para eles, o principal objetivo é ter uma loja com um conceito único e diferenciado para ser uma referência para a marca, sendo uma consequência atender um outro público.

Essa loja conceito tinha algumas especificidades como: o layout de loja diferente e um perfil de funcionário diferenciado (possui um quadro maior de funcionários com perfis especializados - maior conhecimento sobre moda e consultoria para atender as clientes). A principal dificuldade abordada por ela é manter a loja conceito, visto o tamanho do investimento e tentar fazer com que isso se pague, pois muitas vezes, uma loja conceito é muito mais cara que a loja tradicional. Em muitos casos, isso faz parte de uma estratégia de marketing, de ter uma loja num ponto muito nobre, e que isto é válido para colocar a marca em um ponto de maior destaque, apesar de não ser lucrativa. No caso da empresa Y, o investimento na loja conceito tem dado certo (visto que a loja tem seis anos) e que é observada uma consolidação, além do fato de os clientes considerarem essa loja de forma diferente.

Dentre as principais diferenças entre a loja conceito e a loja tradicional levantada, pode ser destacada a mensuração de resultado dos dois tipos de loja. Sobre esse ponto, a respondente disse que cada loja tem seu público-alvo e que é feito o acompanhamento de acordo com as vendas passadas, qual o potencial e como está indo a performance da loja. Esse tipo de acompanhamento de vendas acontece em todas as lojas, a diferenciação no acompanhamento da loja conceito se dá na meta de vendas e na comparação com o ano anterior. Outra diferenciação da loja conceito que foi comentada é em relação aos lançamentos das coleções, onde essas lojas recebem as novas coleções antes das tradicionais. E isso ocorre principalmente porque o lançamento é feito lá, e que é justamente por isso que muitas vezes os eventos são direcionados para os influenciadores.

Foi também perguntada a diferença em relação a alguns aspectos externos e internos da loja conceito e da tradicional. Em relação à fachada (interna e externa da loja), a respondente disse que na loja conceito até o logotipo é diferente, pois é algo que acompanha muito o design da loja, então a mudança vai desde a fachada até a textura do logo (tamanho, cor), pensando no local e design da loja. A exposição das vitrines é mais clean, tem informação, mas menos volume de produtos. A exposição é feita lateralmente, pensando em referências de boutiques e os corredores também são mais largos.

Sobre o layout das lojas, não há diferenciação da loja 
conceito e das tradicionais, o que muda na estratégia é a forma de exposição dos produtos. As lojas se dividem em setores, tanto no tipo de coleção, quanto pensando na democratização da moda. Além disso, tem um volume de produtos um pouco menor que nas lojas tradicionais, onde a exposição é feita muito mais lateralmente (pensando no conceito de boutique) para mostrar mais cartelas de cores do que se fossem feitas exposições frontais. A capacidade de modelos em uma parede é menor para ter essa leveza entre o espaço e o equipamento.

Em relação ao sortimento do produto, foi o mesmo para os dois tipos de loja, mas para coleções exclusivas o volume foi maior na loja conceito. Todos os equipamentos das lojas conceito foram diferentes (equipamento de solo, Ponto De Venda [PDV], caixa, comunicação visual, fixa, diretórios, escada de "Light Emitting Diode" [LED]) e até mesmo o sistema de atendimento. Possuem um sistema mais tecnológico que as outras lojas, onde há um número maior de pessoas para atendimento, sendo que o sistema é muito mais rápido e menos burocrático para fazer troca e pagamento. Além disso, existe um atendimento diferenciado no provador, com consultores de moda que dão dicas de qual produto que fica melhor para aquela cliente, falam das novidades, ou seja, dão um atendimento personalizado através do fornecimento de informação para a cliente.

Um dos questionamentos feitos à respondente foi em relação ao "shopper", se percebe as diferenças entre os dois tipos de loja. A respondente comentou que o "shopper" percebe muito essas diferenças, que comentam, elogiam e até confundem as roupas, achando que elas são diferentes das lojas tradicionais por estarem expostas de formas diferentes do que estão acostumados.

\section{Resultados da pesquisa quantitativa}

No questionário, após apresentados aos estímulos, os respondentes deveriam descrever qualitativamente sua impressão sobre as fotos vistas, sejam as fotos da loja padrão ou as da loja conceito. Essas respostas foram analisadas por meio do método de análise do discurso, a fim de identificar alguns padrões entre as respostas fornecidas.

No que tange à impressão em relação as duas lojas apresentadas, dentre os entrevistados que responderam sobre a loja padrão da empresa $\mathrm{X}$, pode-se destacar que $36 \%$ das respostas referiam-se à loja como moderna e/ou atrativa, mostrando-se entusiasmados com os aspectos físicos da loja. Também podem ser destacadas as respostas que mencionaram organização da loja (11\%), variedade no sortimento $(12 \%)$ e qualidade dos produtos $(3 \%)$. Dentre os entrevistados que responderam sobre a loja conceito da empresa X, 60\% das respostas referiamse à loja como moderna e/ou atrativa, mostrando-se bastante satisfeitos com o visual e os aspectos tanto internos quanto externos da loja. Outro ponto abordado $(11 \%)$ foi que era uma loja diferenciada, tanto em relação à loja padrão da empresa $\mathrm{X}$ quanto das grandes lojas de departamento existentes no mercado brasileiro. De uma forma geral, a loja conceito recebeu melhores avaliações que a loja padrão. Esta foi vista como mais inovadora, com melhores produtos e disposição, fachada mais atrativa e mais diferente do que a loja padrão. Essa pergunta também tinha como objetivo checar se a manipulação havia sido cumprida de forma correta, ou seja, entender se os respondentes haviam diferenciado os dois tipos de loja. Foi feita então uma análise de confiabilidade da escala, com a qual foi obtido um Alpha de Cronbach de 0.717 , valor acima do recomendado (0.7), o que demonstra a confiabilidade da escala.

Portanto, pode-se identificar que os respondentes perceberam de maneira diferente as duas lojas, além de terem fornecido melhores avaliações à loja conceito. A partir disso, pode-se analisar então se a loja conceito influencia na intenção de compra e na imagem da marca.

Primeiramente, os respondentes tiveram que responder uma pergunta em escala Likert sobre a intenção de compra. A escala de intenção utilizada também teve sua confiabilidade testada. Para medição da confiabilidade da escala foi realizada uma análise fatorial dos 5 itens presentes na Likert. De acordo com a análise fatorial, apenas um fator foi extraído e a comunalidade de todos os itens foi superior a 0,5 (mínimo recomendável). Esse fator extraído explica $67 \%$ da variável intenção de compra, um resultado satisfatório. Foi também calculado o Alfa de Cronbach para medir a confiabilidade da escala de intenção de compra, na qual foi obtido o valor 0.874, acima do valor recomendável (0.7) (Tabela 1).

Tabela 1. Total da Variância Explicada

\begin{tabular}{|c|c|c|c|c|c|c|}
\hline \multirow{2}{*}{ Componentes } & \multicolumn{3}{|c|}{ Auto Valores Iniciais } & \multicolumn{3}{|c|}{ Soma dos Valores Extraídos } \\
\hline & Total & Variância & Cumulativo & Total & Variância & Cumulativo \\
\hline & \multicolumn{3}{|c|}{-------- \% --------- } & \multicolumn{3}{|c|}{ - } \\
\hline 1 & 3,373 & 67,455 & 67,455 & 3,373 & 67,455 & 67,455 \\
\hline 2 & 0,637 & 12,739 & 80,195 & & & \\
\hline 3 & 0,464 & 9,271 & 89,465 & & & \\
\hline 4 & 0,291 & 5,822 & 95,288 & & & \\
\hline 5 & 0,236 & 4,712 & 100,000 & & & \\
\hline
\end{tabular}


Foi realizado um teste $\mathrm{T}$ que tinha como variável dependente escalar a intenção de compra e variável independente categórica binária o tipo de loja (loja conceito x loja padrão). Para isso, foi computada uma variável intenção total a partir dos itens presentes na escala Likert de intenção de compra, sendo eles: "Eu gostaria de saber mais sobre a loja conceito da empresa X"; "Comprar na loja conceito da empresa X parece ser uma experiência agradável”; "Eu estou interessado(a) na loja conceito da marca"; "Eu consideraria visitar a loja conceito da empresa X"; "Num futuro próximo, eu pretendo comprar na loja conceito da empresa X".

Ao observar-se a média dos dois grupos em relação à intenção de compra, pode-se perceber que não houve uma diferença de médias muito grande, o que pode ser comprovado através da análise das significâncias (Tabela 2).

Observando o Teste de Levene para igualdade das variâncias na Tabela 3 , notou que a significância do teste foi de 0,103 , ou seja, as variâncias foram iguais.

Tabela 2. Estatísticas do Grupo

\begin{tabular}{rrrrrr}
\hline \multicolumn{2}{c}{ Loja } & N & \multicolumn{1}{c}{ Média } & Desvio Padrão & \multicolumn{2}{c}{ Erro Padrão } \\
\hline \multirow{2}{*}{ Intenção total } & 0,00 & 323 & 4,2793 & 0,70520 & 0,03924 \\
& 1,00 & 297 & 4,1966 & 0,81248 & 0,04714 \\
\hline
\end{tabular}

Tabela 3. Teste de Levene para Igualdade de Variâncias

\begin{tabular}{lllr}
\hline & & F & Significância \\
\hline \multirow{2}{*}{ Intenção total } & Igualdade das variâncias assumidas & 2,662 & 0,103 \\
& Igualdade das variâncias não assumidas & & \multirow{2}{*}{} \\
\hline
\end{tabular}

Analisando a significância do teste de média na Tabela 4, observa-se que foi obtido o valor de 0,176, o que indicou que as médias foram iguais. Infere-se, portanto, que o tipo de loja não influenciou a intenção de compra. Dessa forma, a hipótese 1 deste trabalho foi rejeitada. É importante destacar que esse resultado está de acordo com a própria estratégia das empresas ao abrirem uma loja conceito, como revelado na entrevista realizada com o gestor da empresa X. Sendo assim, o grande objetivo da loja conceito é criar associações positivas para a marca e não as vendas em si. A partir disso, foi analisado se o tipo de loja influencia na imagem da marca.

Foi solicitado que os entrevistados respondessem como eles consideravam a marca da empresa X em uma escala de diferencial semântico de oito itens. A loja conceito foi avaliada pelos respondentes como mais antenada, jovem, confiável, contemporânea, original, amigável, sofisticada e glamourosa que a loja padrão, ou seja, a loja conceito apresenta médias maiores em todos os atributos positivos, indicando que houve uma correlação positiva entre a loja conceito e a imagem da marca.

Novamente, foi realizado um teste $\mathrm{T}$ para comprovar essa influência. Nesse caso, tem-se como variável dependente escalar a imagem da marca e variável independente categórica binária o tipo de loja (Tabela 5). Com os itens agrupados em cargas, foi realizado o teste $\mathrm{T}$.

Tabela 4. Teste t para igualdade das médias

\begin{tabular}{llccrrrr}
\hline & & $\mathrm{t}$ & $\mathrm{dt}$ & P-Valor & $\begin{array}{c}\text { Diferença das } \\
\text { médias }\end{array}$ & $\begin{array}{c}\text { Diferença de erro } \\
\text { padrão }\end{array}$ \\
\hline Intenção & Igualdade das variâncias assumidas & 1,355 & 618,00 & 0,176 & 0,08262 & 0,06098 \\
Total & Igualdade das variâncias não assumidas & 1,347 & 588,52 & 0,178 & 0,08262 & 0,06134 \\
\hline
\end{tabular}

Tabela 5. Estatísticas de Grupo II

\begin{tabular}{|c|c|c|c|c|c|}
\hline & Loja* & $\mathrm{N}$ & Média & Desvio Padrão & Erro Padrão \\
\hline \multirow{2}{*}{ Carga Positiva } & 0,00 & 323 & 4,8173 & 1,28214 & 0,07134 \\
\hline & 1,00 & 297 & 5,0853 & 1,31755 & 0,07645 \\
\hline \multirow{2}{*}{ Carga Negativa } & 0,00 & 323 & 3,2093 & 0,96448 & 0,05367 \\
\hline & 1,00 & 297 & 2,8842 & 1,12047 & 0,6502 \\
\hline
\end{tabular}

Nota:* 0: Grupo Controle (fotos loja padrão); 1: Grupo Experimental (fotos loja conceito) 
Analisando os valores de média dos dois grupos (Tabela 5), pode-se perceber que a média de carga positiva do grupo que viu as fotos da loja conceito foi maior do que a do grupo que viu as fotos da loja padrão, ao mesmo tempo que a média de carga negativa do grupo que viu a loja conceito foi menor do que a do grupo que viu a loja padrão. Isso pode indicar que as pessoas que viram as fotos da loja conceito avaliaram a marca de uma forma mais positiva do que as pessoas que viram as fotos apenas da loja padrão. Assim, pode-se observar se as diferenças de média foram significativas.

Com o Teste de Levene para igualdade das variâncias, observou que a significância do teste foi de 0,773 para a carga positiva, ou seja, as variâncias foram iguais (Tabela 6). Assim, analisou a significância do teste de média. Neste, foi obtido o valor de 0,011, o que comprova que as médias não foram iguais (Tabela 7).

Tabela 6. Teste de Levene para igualdade das variâncias II

\begin{tabular}{llll}
\hline & & F & Significância \\
\hline Carga Positiva & Igualdade das variâncias assumidas & 0,084 & 0,773 \\
& Igualdade das variâncias não assumidas & & \\
Carga Negativa & Igualdade das variâncias assumidas & 4,921 & 0,027 \\
\hline
\end{tabular}

Tabela 7. Teste t para igualdade de médias II

\begin{tabular}{|c|c|c|c|c|c|c|}
\hline & & $\mathrm{F}$ & $\mathrm{dt}$ & P-Valor & $\begin{array}{c}\text { Diferença das } \\
\text { médias }\end{array}$ & $\begin{array}{c}\text { Diferença de Erro } \\
\text { Padrão }\end{array}$ \\
\hline \multirow{2}{*}{ Carga Positiva } & Igualdade das variâncias assumidas & \multirow{2}{*}{0,084} & 618,000 & 0,011 & $-0,26796$ & 0,10445 \\
\hline & Igualdade das variâncias não assumidas & & 610,443 & 0,011 & $-0,26796$ & 0,10457 \\
\hline \multirow{2}{*}{ Carga Negativa } & Igualdade das variâncias assumidas & \multirow{2}{*}{4,921} & 618,000 & 0,000 & 0,32511 & 0,08378 \\
\hline & Igualdade das variâncias não assumidas & & 586,479 & 0,000 & 0,32511 & 0,08430 \\
\hline
\end{tabular}

Para a carga negativa, obtive-se o valor de 0,027 para o teste de Levene, assumindo que as variâncias não foram iguais (Tabela 6). Analisando a significância do teste de média, comprovou que as médias não foram iguais. Assim, pode-se concluir que, de fato, os respondentes que viram as fotos da loja conceito avaliaram a marca de uma forma melhor do que as pessoas que viram as fotos apenas da loja padrão, comprovando a $\mathrm{H} 2$ do presente trabalho.

Assim, de fato, esse ambiente de loja diferenciado não exerce grande influência na intenção de compra dos consumidores e, consequentemente, não se mostrou tão relevante para o faturamento da loja. A hipótese de que a loja conceito influência de forma positiva a intenção de compra, portanto, foi rejeitada. Todavia, a loja conceito mostrou sua relevância em outro aspecto.

A questão principal no que diz respeito à estruturação de uma loja conceito refere-se à criação de associações positivas para a marca, engrandecendo-a, fortalecendo-a e melhorando a forma como os clientes a veem. A melhoria na imagem da marca foi citada na entrevista qualitativa como um dos principais objetivos na abertura de lojas conceito. Por meio do presente trabalho, o atingimento desse propósito pôde ser mensurado. Os resultados da pesquisa quantitativa indicaram que as pessoas avaliaram a marca de uma loja conceito de uma forma mais positiva que de uma marca em que lhes foram apresentadas as fotos de uma loja padrão. A loja conceito, portanto, cumpre seu papel ao trazer associações positivas à marca que carrega, melhorando a imagem da marca da empresa que investiu nesse formato de loja.

\section{Conclusão}

A demasiada concorrência existente entre as marcas fomenta a necessidade de diferenciação. Possuir um ou mais atributos que diferenciem a marca, seus produtos, seu ponto de venda ou mesmo seus funcionários tornouse um diferencial na conquista dos clientes.

O dinamismo e a rápida expansão no mercado de moda é um dos fatores que contribuem para empresas do segmento cada vez mais buscarem a diferenciação. As empresas de vestuário que utilizam estratégia "fast fashion" tem a necessidade de renovação constante, buscando sempre as tendências de moda pelo mundo.

Por meio deste estudo, verificou-se que além de atributos como preço, mix de produtos e comunicação, um dos pontos importantes que faz com que o "shopper" tenha uma boa imagem da marca é o P de "Praça". O ponto de venda, assim, torna-se essencial como uma forma do consumidor ter uma experiência de compra agradável, aumentando a possibilidade de se tornar fiel à marca e de recomendá-la para alguém. 
Com o intuito de ganhar destaque e visibilidade, as empresas de vestuário com estratégia "fast fashion" começaram a inaugurar lojas conceitos, com objetivo de conquistar novos públicos e fazer com que o consumidor crie associações positivas da marca.

Assim, foi visto neste estudo que os resultados indicam que uma loja conceito influencia de forma positiva a imagem de uma marca que investe nesse tipo de estratégia. Porém, foi verificado que esta mesma estratégia não influencia de forma significativa a intenção de compra dos consumidores.

Diante desse cenário de constante mudança e da rápida expansão do setor, é necessário que os varejistas cada vez mais se proponham a criar novas estratégias e pensar em inovações para satisfazer e fidelizar seu público-alvo ao longo prazo, visando se diferenciar dos concorrentes.

Dentre as limitações do presente trabalho, podese destacar, primeiramente, a pequena quantidade de entrevistas em profundidade com gerentes ou pessoas envolvidas na elaboração da loja conceito. Isso acontece devido à grande dificuldade no contato com esses profissionais e na abertura destes em relação aos detalhes da loja e de seus objetivos. Entretanto, os resultados coletados mostram-se apropriados, contendo respostas alinhadas aos resultados obtidos na pesquisa quantitativa.

Outra questão que pode ser apontada como limitação do trabalho refere-se ao fato de que os estímulos presentes no experimento eram fotos, em vez de testar os respondentes no próprio ponto de venda. São muitos os benefícios de um estudo em ambiente controlado, que é o caso do presente trabalho, como o controle de variáveis externas que podem prejudicar ou enviesar os resultados. Todavia, o ambiente controlado impede que haja um maior envolvimento do respondente com o estímulo, uma vez que não propõe uma experiência real de consumo.

Além disso, pode ser destacada como limitação do experimento realizado a utilização da marca da empresa $\mathrm{X}$ para a montagem do estímulo. Apesar de a escolha da marca ter sido feita justamente para que o consumidor mediano não tivesse um conhecimento aprofundado sobre a marca, que não tem atuação no Brasil, a grande maioria dos respondentes conhecia a empresa $\mathrm{X}$, já possuindo uma imagem positiva sobre esta. Isso acontece devido à pouca heterogeneidade da amostra, composta majoritariamente por mulheres jovens de nível socioeconômico alto, outra limitação do trabalho.

Como sugestões para futuros estudos pode ser apontada a realização de pesquisas mais aprofundadas que busquem comparar o comportamento do shopper na loja conceito e na loja padrão, entendendo as diferenças entre ticket médio, frequência de compra, produtos comprados, perfil do “shopper", etc. Além disso, também pode ser sugerida a realização do experimento utilizando, em vez da empresa $X$, marcas brasileiras que seguem a estratégia "fast fashion" e que abriram, paralelamente, lojas conceito. Com os resultados, a validade do presente trabalho pode ser aumentada através da extensão desses estudos para outras marcas.

\section{Referências}

Associação Brasileira da Indústria Têxtil e de Confecção [ABIT]. 2016. Perfil do Setor. Disponível em: <http://www. abit.org.br/>. Acesso em: 27 nov. 2016.

Alvarez, F.S.M. 2012. Trade Marketing: a conquista do consumidor no ponto de venda. Saraiva, São Paulo, SP, Brasil.

Carpenter, J.M.; Fairhurst, A.E. 2005. Consumer shopping value, satisfaction, and loyalty for retail apparel brands. Journal of Fashion Marketing and Management 9 (3): 43-53.

Consoli, M.A.; Guissoni, L.A.; D`Andrea, R. 2011. Shopper Marketing: a nova estratégia integrada de marketing para a conquista do cliente no ponto de venda. Editora Atlas, São Paulo, SP, Brasil.

Darden, W.R.; Erdem, O.; Darden, D.K. 1983. A Comparison and Test of Three Casual Models of Patronage Intentions. North Holland, New York, NY, EUA.

Fionda, A.M.; Moore, C.M. 2009. The anatomy of the luxury fashion brand. Journal of Brand Management 16(5): 347-363.

Frederico, E.; Cantafaro, R.T.; Aydar, F.R.; Shinzaki, A.P.M. 2014. Valor, satisfação e recomendação espontânea para uma marca varejista. Revista Brasileira de Marketing 13(6): 107-123.

Ipar, M.C.S.; Almeida, L.N. 2011. Gestão do Varejo de Moda Feminina: um estudo dos fatores críticos observados em lojas da cidade do Rio de Janeiro. Redige 2(1): 179-198.

Kozinets, R.V.; Sherry, J.F.; Deberry-Spence, B.; Duhacheck, A.; Moore, C. M.; Doherty A. M.; Doyle, S.A. 2010. Flagship stores as a market entry method: the perspective of luxury fashion retailing. European Journal of Marketing 44(1/2): 139-161

Newsom, M.K.; Collier, D.A.; Olsen, E.O. 2009. Using "biztainment" to gain competitive advantage. Business Horizons 52: 67-176.

Serrentino, A. 2016. Varejo e Brasil: reflexões estratégicas. São Paulo, [s.n.]. 